\title{
Predicting Student Performance Using Artificial Neural Network: in the Faculty of Engineering and Information Technology
}

\author{
Samy Abu Naser ${ }^{1}$, Ihab Zaqout ${ }^{1}$, Mahmoud Abu Ghosh ${ }^{2}$, Rasha Atallah ${ }^{2}$ and Eman \\ Alajrami $^{2}$ \\ ${ }^{1}$ Faculty of Engineering \& Information Technology, Al-Azhar University - Gaza, \\ Palestine \\ ${ }^{2}$ Faculty of Information Technology, University of Palestine, Gaza, Palestine \\ sabunaser@gmail.com
}

\begin{abstract}
In this paper an Artificial Neural Network (ANN) model, for predicting the performance of a sophomore student enrolled in engineering majors in the Faculty of Engineering and Information Technology in Al-Azhar University of Gaza was developed and tested.

A number of factors that may possibly influence the performance of a student were outlined. Such factors as high school score, score of subject such as Math I, Math II, Electrical Circuit I, and Electronics I taken during the student freshman year, number of credits passed, student cumulative grade point average of freshman year, types of high school attended and gender, among others, were then used as input variables for the ANN model. A model based on the Multilayer Perceptron Topology was developed and trained using data spanning five generations of graduates from the Engineering Department of the Al-Azhar University, Gaza.

Test data evaluation shows that the ANN model is able to correctly predict the performance of more than $80 \%$ of prospective students.
\end{abstract}

Keywords :Artificial Neural Networks, Student performance, ANN, Education, Predictive Model

\section{Introduction}

The main objective of the student performance prediction system is to determine students who would be expected do well in the Faculty of Engineering and Information Technology in Al-Azhar University. The quality of students enrolled into any university influences the research and training level within the university, and furthermore, has an overall effect on the advances of the country itself, as these students may become a key players in the affairs of the country in all sorts of the economy.

In Al-Azhar University, students get admitted to the Department of Engineering in the Faculty of Engineering and Information Technology after they successfully passed the scientific branch of the high school with at least $70 \%$, students are required to study their freshman year without getting a major in Engineering yet. Once the student finished the freshman year, he or she can major in either Computer and Communication Engineering or Mechatronics Engineering. A student can major in one of the Engineering major if he/she satisfy specific requirements such as High school score, number of credits finished, pass some subjects in the freshman year, such as Math, Electrical Circuits, and Electronics.

It should be noted that this module of predicting student performance will help in identifying which student possibly will succeed in studying Engineering programs. Hence this 
study takes an Engineering approach to make the process a student selecting an Engineering major more effective and efficient. Specifically the study seeks to explore the possibility of using an Artificial Neural Network model to predict the performance of a student before he/she starts his/her sophomore year in Engineering studies.

Naturally one expects the performance of a student to be some type of function with a number of factors (arguments) involving his background and intelligence. It is on the other hand apparent that it will be pretty difficult finding a mathematical model that may adequately model this performance/factors relationship. However one realistic approach for predicting the performance of a student might be by studying his historical data of past students' background and their associated performances.

A practical approach to this type of problem is to apply common regression analysis in which historical data are best fitted to some function. The result is an equation in which each of the inputs $\mathrm{xj}$ is multiplied by a weight wj; the sum of all such products and a constant $\theta$, then gives an estimate of the output $y=\sum w j x j+\theta$, where $j=0 . . n$.

The problem here is the complexity of selecting a proper function competent of capturing all forms of data associations as well as automatically adjusts output in case of further information, because the performance of a candidate is controlled by a number of factors, and this control/association is not going to be any straightforward well-known regression model.

An artificial neural network, which emulates the human brain in solving a problem, is a more common approach that can tackle this kind of problem. Thus, the attempt to put up an adaptive system such as Artificial Neural Network to predict the performance of a student based on the consequence of these factors.

The aims of this study are:

- to identify some suitable factors that affect a student performance,

- to convert these factors into forms appropriate for an adaptive system coding, and

- to model an Artificial Neural Network that can be used to predict a student performance based on some predetermined data for a given student.

\section{Literature Review}

Abu Naser employed Artificial Neural Networks [1] and expert systems [2-6] to obtain knowledge for the learner model in the Linear Programming Intelligent Tutoring System to be able to determine the academic performance level of the learners in order to offer the learner the suitable difficulty level of linear programming problems to solve. Feed forward Backpropagation algorithm was trained with a group of learners data to predict their academic performance. The accuracy of predicting the performance of the learners were very high and thus states that the Artificial Neural Network is skilled enough to make suitable predictions.

Kanakana and Olanrewaju [11] used Artificial Neural Network and linear regression models to predict student performance after access to higher education. Data received from the Tshwane University of Technology was utilized for the study. The total Average Point Scores (APS) students obtained in grade 12 was employed as input variable. The results indicated a better agreement between ANN model prediction and observed values compared to those in the linear regression.

Kyndt et al. in their study predicted general academic performance in the first bachelor year educational sciences, based on students' motivation, approaches to learning, working memory capacity and attention using a neural network analysis. Participants in this study were 128 university students. Results showed that working memory capacity and attention are both good predictors of academic performance, especially for the best and weakest 
performers of the group. Students' motivation and approaches to learning were good predictors for the group of students whose performance was in the middle $60 \%$ [12].

Mukta and Usha carried out an analysis to predict the academic performance of business school graduates using neural networks and traditional statistical techniques and the results were compared to evaluate the performance of these techniques. The underlying constructs in a traditional business school curriculum were also identified and its relevance with the various elements of admission process were presented [13].

Stamos and Andreas presented a model using an artificial neural for predicting student graduation outcomes. The network was developed as a three-layered perceptron and was trained using the backpropagation principles. For training and testing various experiments were executed. In these experiments, a sample of 1,407 profiles of students was used. The sample represented students at Waubonsee College and it was divided into two sets. The first set of 1,100 profiles was used for training and the remaining 307 profiles were used for testing. The average predictability rate for the training and test sets were $77 \%$ and $68 \%$, respectively [14].

\section{The Artificial Neural Networks}

An Artificial Neural Network (ANN) is an arithmetical model that is motivated by the organization and/or functional feature of biological neural networks. A neural network contains an interrelated set of artificial neurons, and it processes information using a connectionist form to computation. As a general rule an ANN is an adaptive system that adjusts its structure based on external or internal information that runs through the network during the learning process. Recent neural networks are non-linear numerical data modeling tools. They are usually used to model intricate relationships among inputs and outputs or to uncover patterns in data. ANN has been applied in numerous applications with considerable attainment [7-8]. For example, ANN have been effectively applied in the area of prediction, handwritten character recognition, evaluating prices of lodging [9-10].

Neurons are often grouped into layers. Layers are groups of neurons that perform similar functions. There are three types of layers. The input layer is the layer of neurons that receive input from the user program. The layer of neurons that send data to the user program is the output layer. Between the input layer and output layer are hidden layers. Hidden layer neurons are only connected only to other neurons and never directly interact with the user program. The input and output layers are not just there as interface points. Every neuron in a neural network has the opportunity to affect processing. Processing can occur at any layer in the neural network. Not every neural network has this many layers. The hidden layer is optional. The input and output layers are required, but it is possible to have on layer act as both an input and output layer [10].

ANN learning can be either supervised or unsupervised. Supervised training is accomplished by giving the neural network a set of sample data along with the anticipated outputs from each of these samples. Supervised training is the most common form of neural network training. As supervised training proceeds the neural network is taken through several iterations, or epochs, until the actual output of the neural network matches the anticipated output, with a reasonably small error. Each epoch is one pass through the training samples. Unsupervised training is similar to supervised training except that no anticipated outputs are provided. Unsupervised training usually occurs when the neural network is to classify the inputs into several groups. The training progresses through many epochs, just as in supervised training. As training progresses the classification groups are "discovered" by the neural network [9]. 
Training is the process by which these connection weights are assigned. Most training algorithms begin by assigning random numbers to the weight matrix. Then the validity of the neural network is examined. Next the weights are adjusted based on how valid the neural network performed. This process is repeated until the validation error is within an acceptable limit [8].

Validation of the system is done once a neural network has been trained and it must be evaluated to see if it is ready for actual use. This final step is important so that it can be determined if additional training is required. To correctly validate a neural network validation data must be set aside that is completely separate from the training data [10].

About $60 \%$ of the total sample data was used for network training in this paper. About $30 \%$ of the total sample data served as test and the remaining $10 \%$ used for validation of the system.

\section{Methodology}

By looking deeply through the literature and soliciting the experience of human experts on student performance, a number of factors that are considered to have an effect on the performance of a sophomore student were outlined. These factors were cautiously studied and synchronized into a convenient number appropriate for computer coding within the environment of the ANN modeling. These factors were classified as input variables. The output variables embody some likely levels of performance of a student in terms of Al-Azhar University grading system.

\subsection{The Input Variables}

The input variables identified are those which can simply be obtained from student file and registrar system. The input variables are:

1. High School score,

2. Results in Math I in the student freshman year,

3. Results in Math II in the student freshman year,

4. Results in Electrical Circuits in the student freshman year,

5. Results in Electronics I in the student freshman year,

6. Number of credits passed in the student freshman year,

7. CGPA of the freshman year,

8. Type of High school whether it is private or public,

9. Location of high School, whether it is in Palestine or outside, and

10. Student's Gender.

Table 1. Input Data Transformation

\begin{tabular}{|c|c|c|c|c|c|c|c|}
\hline $\mathbf{S} / \mathbf{N}$ & $\begin{array}{c}\text { Input } \\
\text { variable }\end{array}$ & \multicolumn{2}{|c|}{ Domain } & $\mathbf{S} / \mathbf{N}$ & $\begin{array}{c}\text { Input } \\
\text { variable }\end{array}$ & \multicolumn{2}{|c|}{ Domain } \\
\hline 1 & $\begin{array}{l}\text { High School } \\
\text { score }\end{array}$ & $\begin{array}{c}\text { Above } 80 \% \\
75-79 \\
70-74\end{array}$ & $\begin{array}{l}1 \\
2 \\
3\end{array}$ & 6 & $\begin{array}{c}\text { Number of credits } \\
\text { passed }\end{array}$ & $\begin{array}{l}32 \text { hours } \\
26-31 \\
24-25\end{array}$ & $\begin{array}{l}1 \\
2 \\
3\end{array}$ \\
\hline 2 & Math I & $\begin{array}{c}\text { Above } 85 \% \\
75-84 \\
60-74\end{array}$ & $\begin{array}{l}1 \\
2 \\
3\end{array}$ & 7 & CGPA of freshman Year & $\begin{array}{c}\text { Above } 90 \% \\
80-89 \\
70-79 \\
65-69\end{array}$ & $\begin{array}{l}1 \\
2 \\
3 \\
4\end{array}$ \\
\hline
\end{tabular}




\begin{tabular}{|c|c|c|c|c|c|c|c|}
\hline 3 & Math II & $\begin{array}{c}\text { Above } 85 \% \\
75-84 \\
60-74\end{array}$ & $\begin{array}{l}1 \\
2 \\
3\end{array}$ & 8 & $\begin{array}{l}\text { Zone of High school } \\
\text { attended }\end{array}$ & $\begin{array}{l}\text { Palestine } \\
\text { Outside of } \\
\text { Palestine }\end{array}$ & $\begin{array}{l}1 \\
2\end{array}$ \\
\hline 4 & Electrical Circuit I & $\begin{array}{c}\text { Above } 85 \% \\
75-84 \\
60-74\end{array}$ & $\begin{array}{l}1 \\
2 \\
3\end{array}$ & 9 & Type of High School & $\begin{array}{l}\text { Private } \\
\text { Public }\end{array}$ & $\begin{array}{l}1 \\
2\end{array}$ \\
\hline 5 & Electronics I & $\begin{array}{c}\text { Above } 85 \% \\
75-84 \\
60-74\end{array}$ & $\begin{array}{l}1 \\
2 \\
3\end{array}$ & 10 & Gender & $\begin{array}{l}\text { Male } \\
\text { Female }\end{array}$ & $\begin{array}{l}1 \\
2\end{array}$ \\
\hline
\end{tabular}

These factors were converted into a format suitable for neural network analysis as shown in Table1.

\subsection{The Output Variable}

The output variable represents the performance of a student on graduation. The output variable is based on the current grading system used in Al-Azhar University. However, for the scope of this paper, the domain of the output variables represents some range of Cumulative Grade Point Averages (CGPA).

Table 2. Output Data Transformation

\begin{tabular}{|c|l|l|}
\hline S/N & $\begin{array}{l}\text { Output } \\
\text { Variable }\end{array}$ & CGPA \\
\hline 1 & Excellent & $90 \%$ and above \\
\hline 2 & Very Good & $80 \%$ and less than $90 \%$ \\
\hline 3 & Good & $70 \%$ and less than $80 \%$ \\
\hline 4 & Poor & $65 \%$ and less than $70 \%$ \\
\hline
\end{tabular}

Table 2 shows the classification of the output variable chosen which are in compliant with the grading system in Al-Azhar University in Gaza.

\section{Design of the Neural Networks}

\subsection{Network Architecture}

The network is a multilayer perceptron neural network using the linear sigmoid activation function as seen in Figure 1. 


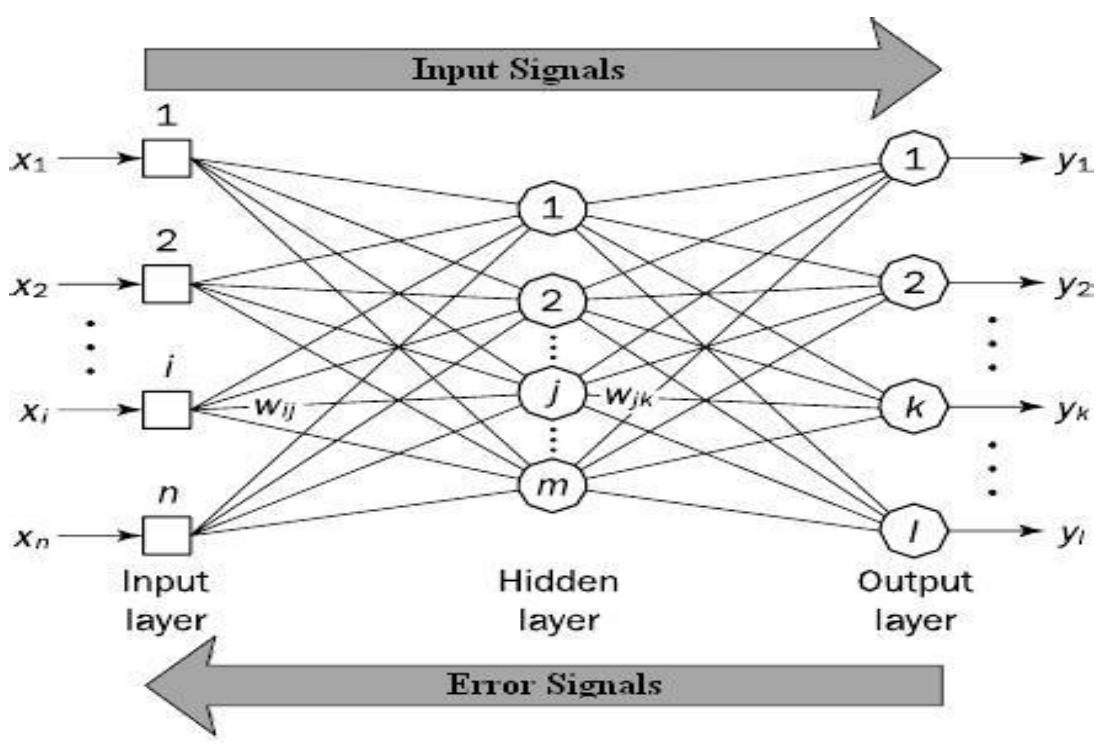

Figure 1. Artificial Neural System Architecture

\subsection{The Back-propagation Training Algorithm}

- Initialize each $\mathrm{w}_{\mathrm{i}}$ to some small random value

- Until the termination condition is met, Do

- For each training example $\left\langle\left(\mathrm{x}_{1}, \ldots \mathrm{x}_{\mathrm{n}}\right), \mathrm{t}\right\rangle$ Do

- Input the instance $\left(\mathrm{x}_{1}, \ldots, \mathrm{x}_{\mathrm{n}}\right)$ to the network and compute the network outputs $\mathrm{o}_{\mathrm{k}}$

- For each output unit k: $\delta_{\mathrm{k}}=\mathrm{O}_{\mathrm{k}}\left(1-\mathrm{O}_{\mathrm{k}}\right)\left(\mathrm{t}_{\mathrm{k}}-\mathrm{O}_{\mathrm{k}}\right)$

- For each hidden unit h: $\delta_{\mathrm{h}}=\mathrm{O}_{\mathrm{h}}\left(1-\mathrm{O}_{\mathrm{h}}\right) \sum_{\mathrm{k}} \mathrm{W}_{\mathrm{h}, \mathrm{k}} \delta_{\mathrm{k}}$

- For each network weight $\mathrm{w}_{\mathrm{j}}$ Do

- $\mathrm{w}_{\mathrm{i}, \mathrm{j}}=\mathrm{w}_{\mathrm{i}, \mathrm{j}}+\Delta \mathrm{w}_{\mathrm{i}, \mathrm{j}}$, where $\Delta \mathrm{w}_{\mathrm{i}, \mathrm{j}}=\eta \delta_{\mathrm{j}} \mathrm{x}_{\mathrm{i}, \mathrm{j}}$ and $\eta$ is the learning rate.

\section{Evaluation of Neural Network}

As stated earlier, the purpose of this experiment was to predict the sophomore student performance in the Faculty of Engineering and Information Technology. We used feed forward Backpropagation, which provides the facility to implement and test the neural network and its learning algorithm. Our neural network is a feed-forward network, with Single input layer (10 inputs), a hidden layer (6 inputs) and a single Output layer (4 outputs).

A total of 150 sophomore students records were used in the analysis. About $60 \%$ of the total data (i.e. 90 students) were used as the training set, $30 \%$ (i.e. 45 students) as the testing set, and $10 \%$ (i.e. 15 students) used for cross validation.

After the training and cross validation, the network was tested with the test data set and the following results were obtained. This involves given the input variable data to the network without the output variable results. The output from the network is then compared with the actual variable data.

The neural network was able to predict accurately 11 out of 13 for the excellent data (which represents students CGPA in range of $90 \%$ to 100\%), 10 out of 12 of the very good data (which represents students with CGPA in range of $80 \%$ to less than $90 \%$ ) and 9 out of 11 of the good data (which represents students with CGPA in range of $70 \%$ to less than $80 \%$ ), and 8 out of 9 of the poor data (which represents students with CGPA in range 65\% and less 
than $70 \%$ ) used to test the Network's topology. This gives an accuracy of $85 \%$ for Excellent, $83 \%$ for Very Good, $82 \%$ for Good, and $88 \%$ for the Poor classification. This indicates an overall accuracy of $84.6 \%$ for the Artificial Neural network's which a good performance (See Figure 2) is.

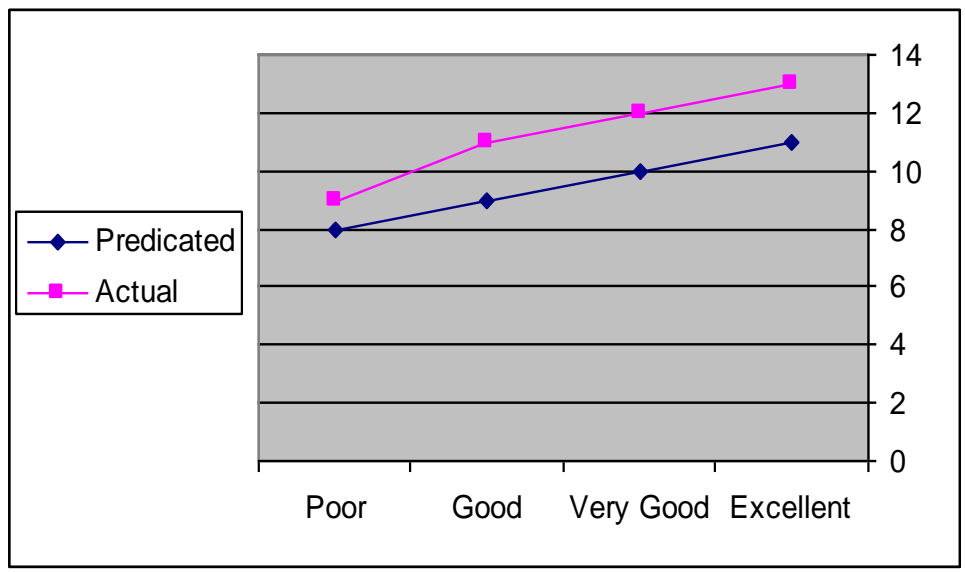

Figure 2. Performance of the Neural Network Model

\section{Conclusion}

An artificial Neural Network model for predicating student performance in the Faculty of Engineering and Information Technology was presented. The model used feed forward backpropagation algorithm for training. The factors for the model were obtained from student registration records. The model was tested and the overall result was $84.6 \%$. This study showed the potential of the artificial neural network for predicating student performance.

\section{References}

[1] S. Abu Naser, "Predicting Learners Performance Using Artificial Neural Networks In Linear Programming Intelligent Tutoring Systems", IJAIA, vol. 3, no. 2, (2012).

[2] S. Abu Naser and Abu O. Zaiter, "An Expert System For Diagnosing Eye Diseases Using Clips", Journal of Theoretical and Applied Information Technology, vol. 5, no. 4, (2008).

[3] S. Abu Naser and A. Akkila, "A proposed Expert System for Skin Diseases Diagnosis", Journal of Applied Sciences Research, vol. 4, no. 12, (2008).

[4] S. Abu Naser, M. Baraka and A. Baraka, "A Proposed Expert System For Guiding Freshman Students In Selecting A Major In Al-Azhar University", Gaza, Journal of Theoretical and Applied Information Technology, vol. 4, no. 9, (2008).

[5] S. Abu Naser, K. Kashkash and M. Fayyad, "Developing an Expert System for Plant Disease Diagnosis", Journal of Theoretical and Applied Information Technology, vol. 1, no. 2, (2008).

[6] S. Abu Naser, A. Al-Masri, Y. Abu Sultan and I. Zaqout, "A Prototype Decision Support System for Optimizing the Effectiveness of E-learning in Educational Institutions", International Journal of Data Mining \& Knowledge Management Process (IJDKP), vol. 1, no. 4.

[7] A. Lotfi and A. Benyettou, "Using Probabilistic Neural Networks for Handwritten Digit Recognition", Journal of Artificial Intelligence, vol. 4, no. 4, (2011).

[8] P. Khanale and S. Chitnis, "Handwritten Devanagari Character Recognition using Artificial Neural Network", Journal of Artificial Intelligence, vol. 4, no. 1, (2011).

[9] P. Eriki and R. Udegbunam, "Application of neural network in evaluating prices of housing units in Nigeria: A preliminary investigation", J. of Artificial Intelligence, vol. 3, no. 1, (2010).

[10] H. Martin and D. Howard, "Neural Network Design", 2nd Edition, Martin Hagan (2014).

[11] G. Kanakana1, and A. Olanrewaju, "Predicting student performance in Engineering Education using an artificial neural network at Tshwane university of technology", ISEM 2011 Proceedings, (2011) September 21-23, Stellenbosch, South Africa. 
[12] E. Kyndt, M. Musso, E. Cascallar and F. Dochy, "Predicting academic performance in higher education: Role of cognitive, learning and motivation", Earli Conference 2011, 14th edition, Exeter, UK, (2011).

[13] P. Mukta and A. Usha, "A study of academic performance of business school graduates using neural network and statistical techniques", Expert Systems with Applications, Elsevier Ltd., vol. 36, no. 4, (2009).

[14] K. Stamos and V. Andreas, "An Artificial Neural Network for Predicting Student Graduation Outcomes", Proceedings of the World Congress on Engineering and Computer Science (2008) "WCECS 2008", San Francisco, USA. 